\title{
Quantifying Space Heating Stove Emissions Related to Different Use Patterns in Mongolia
}

\author{
Randy L. Maddalena ${ }^{1}$, Melissa M. Lunden ${ }^{1}$, Daniel L. Wilson ${ }^{1,2}$, Cristina Ceballos ${ }^{1,2}$, Thomas W. Kirchstetter ${ }^{1}$, \\ Jonathan L. Slack ${ }^{1} \&$ Larry L. Dale ${ }^{1}$ \\ ${ }^{1}$ Lawrence Berkeley National Laboratory, Berkeley, CA, USA \\ ${ }^{2}$ University of California, Berkeley, CA, USA \\ Correspondence: Larry L. Dale, Lawrence Berkeley National Laboratory, Sustainable Energy Systems Group, \\ Energy Efficiency Standards Group, Lawrence Berkeley National Laboratory, 1 Cyclotron Road MS 90R4000, \\ Berkeley CA 94720, USA. Tel: 1-(510) 495-2477. E-mail: LLDale@lbl.gov
}

Received: August 28, 2014 Accepted: September 16, 2014 Online Published: November 26, 2014

doi:10.5539/eer.v4n3p147 URL: http://dx.doi.org/10.5539/eer.v4n3p147

\begin{abstract}
A major source of particulate matter pollution in Mongolia's capital, Ulaanbaatar, is emissions from traditional coal-burning space-heating stoves. Significant investment has been made to replace traditional highly polluting heating stoves with improved low-emission high-efficiency stoves. Performance testing that has been undertaken to support the selection of replacement stoves is typically based on manufacturers' recommended operating procedures, which may not be representative of the operating procedures used in homes. The objective of this research is to evaluate factors that influence stove emissions under typical field operating conditions. A highly-instrumented stove testing facility was constructed to allow for rapid and precise adjustment of factors influencing stove performance. Tests were performed using one of the improved stove models currently available in Ulaanbaatar. Complete burn cycles were conducted with coal from the Ulaanbaatar region using various startup parameters, refueling conditions, and fuel characteristics. Measurements were collected simultaneously from undiluted chimney gas, diluted chimney gas, and plume gas drawn from a dilution tunnel above the chimney. Ignition events lead to increased PM emissions with more than $98 \%$ of PM mass emitted during the startup and refueling process. However, emissions during refueling are of particular interest, both because refueling is common and because refueling associated emissions appear to be very high. CO emissions are distributed more evenly over the burn cycle, peaking during ignition and late in the burn cycle. We anticipate these results being useful, in combination with behavioral surveys, for quantifying public health outcomes related to the distribution of improved stoves and to identify opportunities for improving and sustaining performance of the new stoves.
\end{abstract}

Keywords: air pollution, coal, laboratory testing, particulate matter, Ulaanbaatar

\section{Introduction}

Air pollution levels in Ulaanbaatar, Mongolia's capital, are among the highest in the world (World Bank, 2011). The primary source of particulate matter pollution in and around Ulaanbaatar is wind-blown dust and combustion products related to transportation, energy, and in-home heating and cooking (Davy et.al., 2011; Lodoyasamba \& Pemberton-Pigott, 2011). The traditional coal-fired space heating stoves used in the Ger (tent) neighborhoods around Ulaanbaatar are a major source of particulate matter pollution during the winter months (Allen, et al, 2013; Iyer, Wallman \& Gadgil, 2010).

Significant investment has been made to replace traditional space heating stoves with improved low-emission high-efficiency stoves. Selection of these high-performance heating stoves is based on scripted performance and emission testing protocols that are often based on manufacturers' recommended operating procedures. These idealized test conditions demonstrate the stoves' optimal performance but they do not account for non-ideal stove operation by users, and therefore manufacturers' results may not be representative of true in-field performance and emissions.

Pemberton-Pigott (2011) summarized a large number of stove performance tests conducted at the Stove Emissions and Efficiency Testing (SEET) Laboratory in Ulaanbaatar, noting that stove performance was 
impacted by how the stoves were actually being used compared to the recommended operating method. Furthermore, Lobscheid, Fitts, Lodoysamba, Maddalena \& Dale (2014) report that field operation of improved stoves varies significantly from manufacturers' recommended operating methods, but emission measurements for the range of operating methods observed in the field are not available.

Stove performance in the field can vary widely due to differences in environmental conditions and operating behaviors. For example, a migrating pyrolytic front stove, often called a "TLUD" (Top-Lit/Up-Draft) is designed to have a stack of fuel batch-loaded into a combustion chamber and then ignited from the top (Figure 1). Improved emissions performance for this style of stove is achieved by the slow downward migration of the pyrolytic front. However, this design requires the stove to cool below the fuel ignition temperature before refueling. If cold fuel is added on top of hot embers, the fuel stack could ignite from below resulting in an updraft scenario marked by reduced performance and a significant increase in emissions.

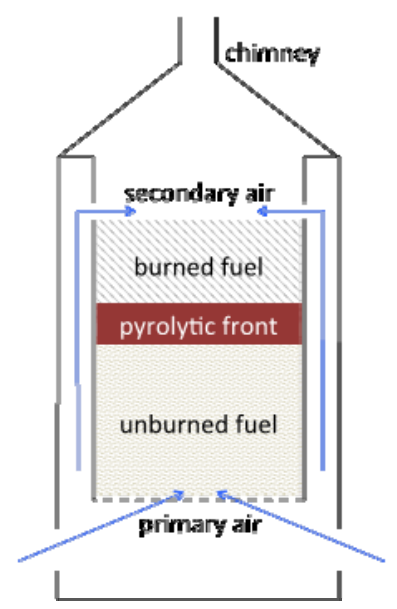

Figure 1. Functional schematic of a "TLUD" heating stove

Lobscheid et al. (2014) observed three main stove operating behaviors for TLUD stoves during a field survey. These include: 1) cold start in which the stove is empty and cold prior to loading and lighting fuel from the top (i.e., per manufacturers recommended operating procedure); 2) warm refueling in which cold fuel is added atop residual embers and ash in the combustion chamber. Residual heat being insufficient for immediate ignition, the fuel is lit from the top, but the pre-warmed stove could subsequently ignite from below; and 3) hot refueling where sufficient embers, flames, and heat is present in the combustion chamber at the time of refueling to ignite the fresh, cold fuel upon reloading with no top-lighting. The frequency of occurrence of each of these stove operating behaviors is discussed by Lobscheid et al. (2014). Emission factors for each scenario are needed to support real-world assessments of stove performance and to estimate stove emissions for exposure and health risk assessments. In addition, field-representative emission factors may help identify opportunities for additional improvements to stove design.

The combination of stove design, fuel characteristics, and operational factors, along with the complex nature of the combustion process, leads to significant levels of variability and uncertainty in emission measurements. Some of the variability is explained by differences in environmental and operational factors (field variability), but even more may be from measurement error (measurement uncertainty or measurement bias) in the field or in the laboratory.

Most of the Mongolian stove studies have relied on a measurement technique known as the "chimney method" in which emissions are sampled directly from the chimney using a custom dilution apparatus (Pemberton-Pigott, 2011). The chimney method involves a number of steps including sampling hot gas from the base of the chimney just above the fuel bed, applying a constant stream of clean dry dilution air at the inlet of a sample line, cooling of the gas stream as it travels from the sampling port to the analyzer(s), fog, water and soot condensation management in the inlet and sampling lines, and determination of undiluted chimney exhaust flows from fuel burn rates and mass balance calculations. Each of these steps can contribute to measurement uncertainty. Additionally, the chimney method "freezes" emissions sampled at the base of the chimney using cold dilution air. However, in a normal chimney, high temperatures, concentrated aerosols, and volatile gases lead to evolution of 
the aerosol inside the chimney; "frozen" aerosol measurements taken from the base of the chimney may differ from air quality-relevant emissions exiting the top of the chimney. Finally, although the chimney method is used extensively in Mongolian stove testing projects, there are virtually no published studies validating the robustness of this method.

In contrast, several published studies explain and support the use of a dilution tunnel approach in which samples are drawn from a calibrated dilution chamber mounted above the chimney. Advantages of the dilution chamber approach including (a) the method is focused on emission samples drawn from an ambient air quality-relevant location - the exit of the chimney and (b) the samples are diluted and measured in a large dilution tunnel rather than a small tube - an approach that virtually eliminates particle clogging and eases the sample dilution process. However, the dilution chamber approach is difficult to apply in the field because it requires accessing the top of the chimney.

A testing facility was designed and constructed at Lawrence Berkeley National Laboratory (LBNL) for measuring emissions from space heating stoves under simulated field-use conditions. It is important to understand differences between the sampling methods, therefore the LBNL test facility was instrumented with both the direct chimney dilution sampler and the top of chimney dilution tunnel. In this paper we report on the design of the LBNL test facility, the testing methods, and the results of emissions testing conducted on a Silver-mini (small Turkish) top-lit up-draft (TLUD) stove under several start-up and refuel scenarios. We evaluate the testing results in the context of three other studies of PM 2.5 emissions from heating stoves used in Mongolia. These studies differ according to test location (lab, field, or test Ger), measurement technique (chimney or exhaust dilution), and focus (fuel type, fueling behavior, and climate). We conclude with a discussion of the sources of variability and uncertainty in emissions testing and a summary of recommendations for future experiments to improve the estimation of actual emissions from improved space heating stoves.

\section{Method}

\subsection{Experimental Facility}

The LBNL test facility combines the direct flue-gas dilution approach (Iyer et.al, 2010; Pemberton-Pigott, 2011) and the dilution tunnel approach (Gullett, Touati \& Hays, 2003; Purvis, McCrillis \& Kariher (2000); Pettersson, Lindmark, Ohman, Nordin, Westerholm \& Boman, 2010; Pettersson, Boman, Westerholm, Bostrom \& Nordin, 2011; Boman, Nordin, Westerholm \& Pettersson, 2005, Boman, Pettersson, Westerholm, Bostrom \& Nordin 2011). The experimental facility, illustrated in Figure 2, was constructed inside a large high-ceilinged metal building. A brief description of the facility is provided below with more details in the Maddalena, Lunden, Wilson, Ceballos, Kirchstetter, Slack \& Dale, 2014).

The test stove is placed on a platform scale with digital readout that records continuous mass during test burns. The continuous mass is used along with fuel composition to determine flue gas flow rate using a mass balance. The exhaust from the combustion chamber is vented to a section of chimney $(0.127 \mathrm{~m}$ diameter $\times 0.610 \mathrm{~m}$ height $)$ that contains the flue-gas dilution apparatus. A standard metal chimney $(0.102 \mathrm{~m}$ diameter $\times 2.428 \mathrm{~m}$ height $)$ is fit to the top of the flue-gas dilution apparatus. The dilution tunnel is suspended above the stove at $2.5 \mathrm{~m}$ height and the chimney extends $0.25 \mathrm{~m}$ into the dilution tunnel through a slightly enlarged hole. The chimney is free standing supported with cables to allow for continuous mass determination during a burn.

The dilution tunnel is constructed from a $1.83 \mathrm{~m}$ length of $0.61 \mathrm{~m}$ diameter duct suspended horizontally above the stove. The air inlet to the dilution tunnel on the right side of Figure 2 has an adjustable diameter to allow for control of the pressure in the dilution tunnel to adjust the chimney draft. The outlet from the dilution tunnel feeds into a $0.15 \mathrm{~m}$ diameter duct that passes through an adjustable damper to an industrial blower before exhausting from the building through a spark-arresting screen. Flow through the dilution tunnel is controlled and monitored by the iris damper and pressure inside the dilution tunnel is controlled by the size of the inlet. 


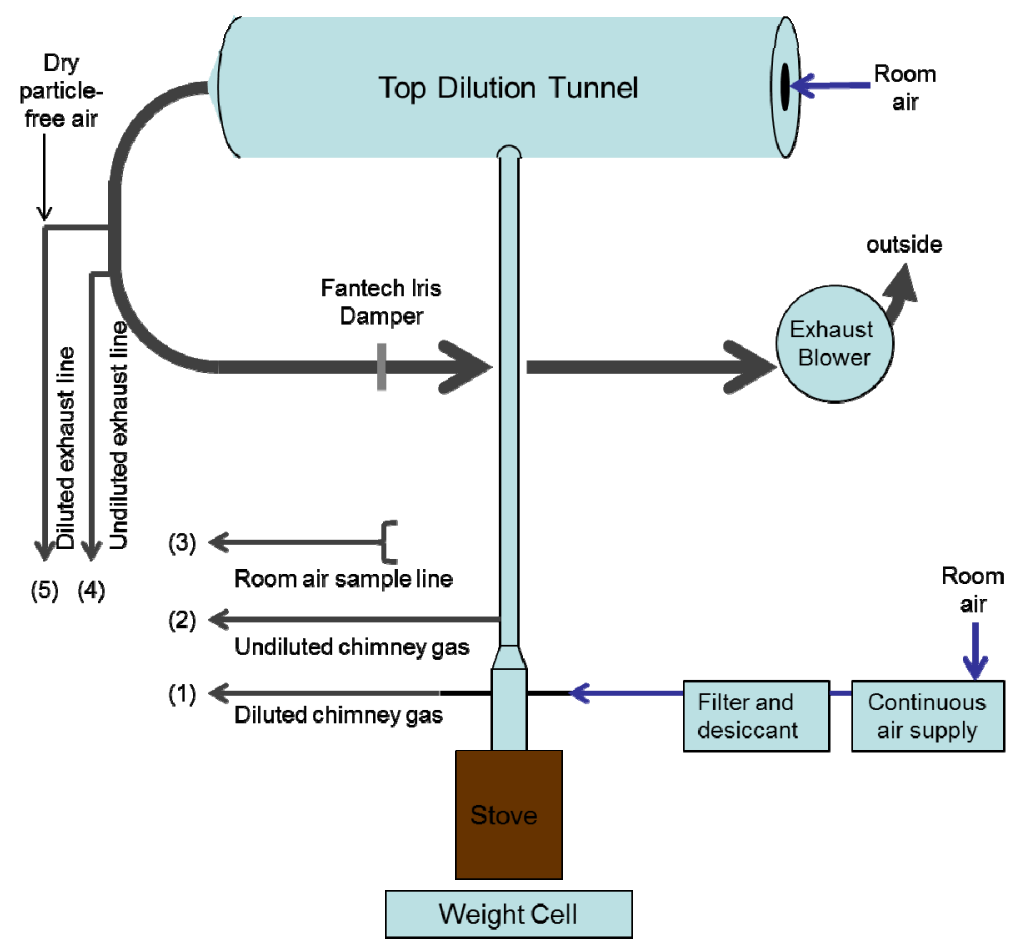

Figure 1. Schematic of LBNL Stove Testing Facility. All stove emissions and effluent from sample lines are exhausted outside. The flue-gas dilution apparatus is illustrated in Figure 2 and the numbered sampling lines are shown in detail in Figure 3

The chimney dilution apparatus is made up of two $12.7 \mathrm{~mm}$ heavy-walled stainless steel pipes mounted in adjustable sleeves. The sleeves are affixed on either side of the chimney, and the stainless steel pipes are allowed to slide so they meet near the center of the chimney. The tips of the pipes are milled so that the pipe delivering particle free dry air has a small orifice and the receiving pipe has an inverted cone shape. The pipes are mounted approximately $1 \mathrm{~mm}$ apart to allow chimney gas to be drawn into the sampling line. The difference in flow rate in the delivery line and the sample line are used to control the dilution. The design is based on that of the SEET lab (Pemberton-Pigott, 2011) where chimney gas is rapidly extracted from the chimney and diluted with dry particle free air to prevent moisture/aerosol condensation in the sample line and to bring gas concentrations within operational limits of the analyzers. The particle-free dry air is generated using a continuous flow compressor (Dewalt model D55146) and the air passes through a coalescing filter, two drying cartridges (Parker/Watt dryrite model DD15), a HEPA particle filter, and finally a mass flow controller for continuous metered flow (Alicat 0-20 LPM).

\subsection{Instrumentation}

There are five sample lines built into the system (see Figure 4) that measure diluted and undiluted gas from the chimney, diluted and undiluted gas from the dilution tunnel, and room air. In addition, the temperature is measured continuously in the room, inside the chimney just above the stove, inside the chimney at ceiling height ( 8 foot off floor), and in the 6-inch exhaust duct downstream from the upper dilution tunnel (Figure 2). Pressure is measured in the chimney just above the stove, in the chimney at the ceiling height, and in the exhaust duct on each side of the FanTech iris damper. 


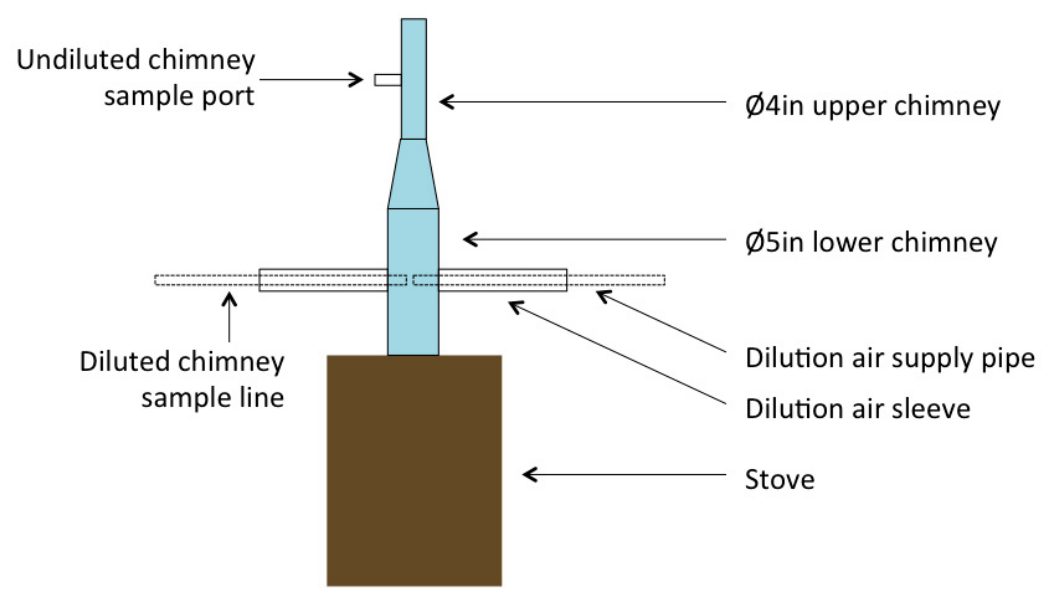

Figure 2. Detailed figure of the chimney dilution sampling system

Sample line 1 provides diluted chimney gas that passes through a 2.5 micron cyclone before being split to a gas analyzer (CAI 600 Series Model $602 \mathrm{P}-\mathrm{CO}_{2} / \mathrm{CO} / \mathrm{O}_{2}$ ), real time PM mass sensor (TSI DustTrak II model 8530), an integrated PM mass measurement (25 mm Teflon filters) and excess flow for additional lines to mount other instruments or gas samples as needed. Sample line 2 is undiluted chimney gas drawn through a coalescing filter filled with glass beads to reduce static volume followed by a Nafion drying column (MD-110-125-4) with dry air counter current flow (5 LPM) followed by a second gas analyzer (CAI 600 Series model $602 \mathrm{P}-\mathrm{CO}_{2} / \mathrm{CO} / \mathrm{O}_{2}$ ). Line 3 samples room air through a $\mathrm{CO}_{2}$ analyzer (Li-Cor model LI-820). Sample line 4 is drawn directly from the exhaust after it exits the upper dilution tunnel and is sampled through a second $\mathrm{CO}_{2}$ analyzer $(\mathrm{Li}-\mathrm{Cor}$ model LI-820). The flow through both Li-Cor samplers is controlled by constant vacuum and critical orifice. Sample line 5 provides a secondary dry particle free source of air for additional dilution of the exhaust before running through a second real-time PM mass sensor (TSI DustTrak II model 8530).

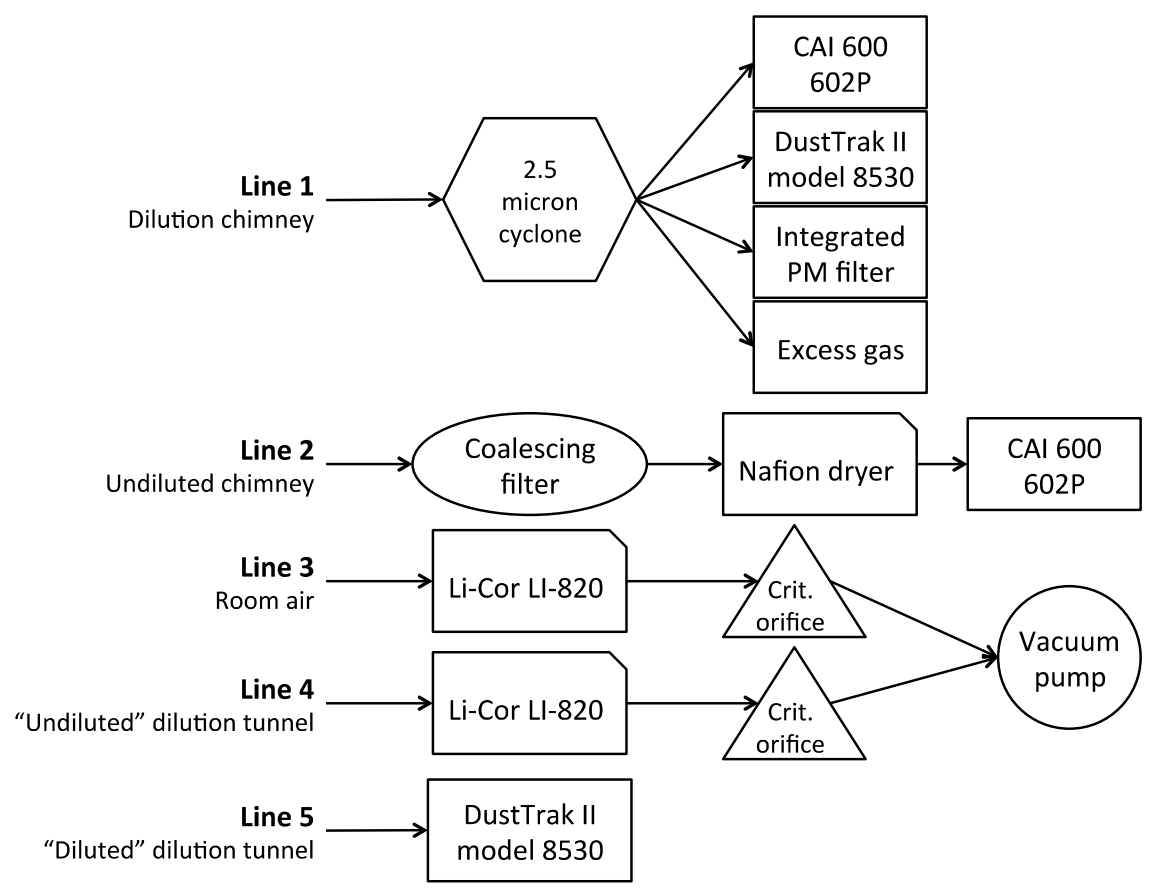

Figure 3. Sample lines and instruments 


\subsection{Emissions Testing}

All emission tests were performed using a Silver-mini (small Turkish) TLUD stove and Nailakh coal, one of the most commonly used fuels in Ulaanbaatar (World Bank, 2011). The coal was shipped in sealed barrels from Mongolia to LBNL. The typical test included a cold start with approximately $10 \mathrm{~kg}$ of fuel followed by a refueling event consisting of approximately $5 \mathrm{~kg}$ fuel. The cold-start was accomplished by filling the fire-box with the specified amount of coal, placing a small amount of paper and dry wood on top of the coal and lighting the paper resulting in a "top lit down draft" condition. The refueling events were conducted at different stages of the burn with the earliest refueling event occurring as soon as the coal fuel bed collapsed and the latest refueling conducted while enough embers remained to ignite the coal. Some of the startup events used less than the $10 \mathrm{~kg}$ of coal to explore the impact on emissions during ignition. A summary of experiments is provided in Table 1. A stove conditioning burn was conducted prior to the first test to remove residues from the stove and to identify appropriate dilutions for the sampling lines.

Table 1. Summary of Experiments

\begin{tabular}{|c|c|c|c|}
\hline Test Date & Test Name & Stages of burn & Description of test \\
\hline \multirow[t]{2}{*}{ 20-March } & \multirow{2}{*}{$\begin{array}{l}\text { Typical burn; } \\
\text { early refuel }\end{array}$} & Cold-start & Typical mass of fuel at both ignitions \\
\hline & & Early hot-refuel & Hot refueling performed just after fuel bed collapse \\
\hline \multirow[t]{3}{*}{ 21-March } & \multirow{3}{*}{$\begin{array}{l}\text { Typical burn; } \\
\text { late large refuel }\end{array}$} & Cold-start & Typical mass of fuel at startup \\
\hline & & Late hot-refuel & Extra fuel used at refueling \\
\hline & & & ng perfor \\
\hline \multirow[t]{2}{*}{ 27-March } & \multirow{2}{*}{$\begin{array}{l}\text { Typical burn; } \\
\text { late refuel }\end{array}$} & Cold-start & Typical mass of fuel at both ignitions \\
\hline & & Late hot-refuel & Hot refueling performed late in run \\
\hline 28-March & $\begin{array}{l}\text { Typical burn; } \\
\text { no refuel }\end{array}$ & Cold start & $\begin{array}{l}\text { Stove did not start initially. } \\
\text { Typical mass of fuel used at startup } \\
\text { No refuel event }\end{array}$ \\
\hline \multirow[t]{4}{*}{ 13-June } & & & Light load of fuel used at startup \\
\hline & Light burn; & Cold-start & Typical mass of fuel used at refueling \\
\hline & late refuel & Late hot-refuel & Refueling performed late in run \\
\hline & & & Only exhaust dilution line used in PM sampling \\
\hline
\end{tabular}

\subsubsection{Setting the Standard Chimney Draft}

When conducting emission testing under laboratory conditions, it is important to set the chimney draft at a representative value for field conditions. The chimney draft (at ceiling height) for this study is set to be representative of winter conditions in Ulaanbaatar. We assume that the typical chimney consists of a 10 foot section of 4 inch pipe extended 1 meter above the roof line (ceiling height of a Ger). The air inlet to the stove is open at $\sim 6$ inches above the floor. Indoor and outdoor temperatures are $20^{\circ} \mathrm{C}$ and $-20^{\circ} \mathrm{C}$ respectively, with a 5 meters-per-second wind speed at the top of the chimney.

The draft in this case is dominated by wind effect where the typical flue wind pressure coefficient is about -0.5 so the pressure gradient caused by wind $\left(d P_{\text {wind }}\right)$ is estimated as

$$
d P_{\text {wind }}=0.5 \rho * C p * V^{2}
$$

Where $\rho$ is the density of air, $C_{p}$ is the specific heat of chimney gases and $V$ is wind speed at the top of the chimney. The resulting draft at ceiling height for wind effect is approximately - 7.5 Pa. For stack effect we assume $1.45 \mathrm{~m}$ of chimney is indoors and $1 \mathrm{~m}$ is outdoors. With no fire, the temperature of air in the flue is the same as the room temperature therefore the inside section of chimney generates no stack effect. The outside section of chimney generates a draft caused by the temperature gradient calculated as

$$
d P_{\text {stack }}=\rho \times g \times h \times d T / T
$$

Where $\rho$ is the density of air, $g$ is acceleration of gravity $\left(-9.8 \mathrm{~m} / \mathrm{s}^{2}\right), h$ is the height of the section of chimney and $d T / T$ is the temperature gradient relative to room temperature $(\mathrm{K})$. The resulting draft for stack effect is approximately - 1.7 Pa. So the total draft $\left(d P_{\text {wind }}+d P_{\text {stack }}\right)$ at ceiling height at startup is $-7.5-1.7=-9.2 \mathrm{~Pa}$. We set the draft to a value between -7 and $-10 \mathrm{~Pa}$. The draft in the chimney is set by controlling flow in the dilution tunnel above the chimney. 


\section{Results}

We found that virtually all of PM emissions (by mass) occur during ignition events (i.e., when the fuel is lit by the operator or by residual embers/flame in the fire box), while $\mathrm{CO}$ emissions were more widely distributed over different phases of the burn (Table 1). For the ignition events, we found that refueling produced up to five times more PM emissions than initial cold starts, with the one exception being an early refueling when the temperature in the fire-box was above 450 Celsius. For the cold starts, it appears that the majority of PM is caused by the ignition and combustion of wood and paper and only a moderate amount of PM is caused by the ignition of coal. Not surprisingly, for refueling events, all of the PM emissions result from the combustion of coal.

PM emission factors integrated over the entire burn and measured using the exhaust technique range from $3-8$ grams per $\mathrm{kg}$ fuel consumed (Table 1). Emission factors for the ignition period range from $1-16 \mathrm{~g} / \mathrm{kg}$ fuel consumed for cold-start conditions and from $7-81 \mathrm{~g} / \mathrm{kg}$ fuel consumed for refuel events. The duration of ignition phases varied from run to run (range $21-89$ minutes for cold starts and $20-41$ minutes for refueling events.

While fuel consumption was measured directly during this study, measuring fuel consumption in the field during different phases of a burn is not feasible. Fortunately, particulate emissions result almost entirely from ignition events and are relatively consistent regardless of the amount of fuel or the duration of the ignition phase (for the conditions tested in this study). Therefore, we recommend reporting emissions per ignition event, which could greatly simplify the calculation of source terms for air quality modeling. As such, we found PM2.5 emission rates of 15 grams per cold start event ( $\pm 80 \%$ coefficient of variation) and 60 grams of PM2.5 per refuel event ( \pm $80 \%$ coefficient of variation).

The large variance in results is due in part to the relatively small number of experiments and large number of factors that influence emissions. The variance could be reduced with experiments that focus on a small number of covariant factors. For example, we combined differences in operational behaviors with differences in fuel characteristics (size, moisture). We also varied the mass of coal loading and the amount of ash removed from the fire-box prior to refueling. The lack of experimental replicates limits our ability to provide a reliable estimate of uncertainty, but the largest contributor to uncertainty appears to arise from test imprecision — as suggested by the wide variation of emission estimates using the chimney technique.

Table 2. Summary of test data

\begin{tabular}{|c|c|c|c|c|c|c|c|}
\hline Test Name and Type & & & $\begin{array}{c}\text { Typical } \\
\text { burn; early } \\
\text { refuel }\end{array}$ & $\begin{array}{c}\text { Typical } \\
\text { burn; late } \\
\text { large } \\
\text { refuel }\end{array}$ & $\begin{array}{c}\text { Typical } \\
\text { burn; late } \\
\text { refuel }\end{array}$ & $\begin{array}{c}\text { Typical } \\
\text { burn; no } \\
\text { refuel }\end{array}$ & $\begin{array}{l}\text { Light } \\
\text { burn; late } \\
\text { refuel }\end{array}$ \\
\hline Metric & Test Type & Unit & 20-Mar & 21-Mar & 27-Mar & 28-Mar & 13-Jun \\
\hline \multicolumn{2}{|l|}{ Test Duration } & $\overline{m i n}$ & 452 & 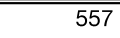 & 508 & 384 & 192 \\
\hline \multicolumn{2}{|l|}{ Initial Mass of Coal } & $\mathrm{kg}$ & 10.8 & 10.6 & 10.0 & 10.0 & 6.0 \\
\hline \multicolumn{2}{|l|}{ Initial Mass of Wood and Paper } & $\mathrm{kg}$ & 0.3 & 0.5 & 0.4 & 0.5 & 0.5 \\
\hline \multicolumn{2}{|l|}{ Refuel Mass of Coal } & $\mathrm{kg}$ & 4.7 & 6.8 & 5.0 & 0.0 & 4.9 \\
\hline \multicolumn{2}{|l|}{ Stove Temperature at Refuel } & C & 638 & 451 & 438 & NA & 364 \\
\hline \multirow{2}{*}{ Total PM Emissions During Full Test } & chimney & $\bar{g}$ & 19.7 & 32.85 & NA & 3.19 & $\overline{N A}$ \\
\hline & exhaust & g & 34.2 & 107 & 111 & 28.6 & 32.5 \\
\hline \multirow{2}{*}{$\%$ of Total PM Emissions Occuring During Refuel } & chimney & $\%$ & $2.6 \%$ & $63.7 \%$ & $99.4 \%$ & NA & NA \\
\hline & exhaust & $\%$ & $25.3 \%$ & $83.1 \%$ & $95.2 \%$ & NA & $96.5 \%$ \\
\hline \multirow{2}{*}{$\%$ of Total PM Emissions Occuring During Ignition Events } & chimney & $\%$ & $99.5 \%$ & $99.7 \%$ & $99.4 \%$ & $98.1 \%$ & NA \\
\hline & exhaust & $\%$ & $98.5 \%$ & $99.0 \%$ & $99.2 \%$ & $98.3 \%$ & $99.1 \%$ \\
\hline \multirow{2}{*}{ PM Emission Factor (PM emissions/fuel consumed) During Full Test } & chimney & $\mathrm{g} / \mathrm{kg}$ & 1.45 & 2.30 & NA & 0.33 & NA \\
\hline & exhaust & $\mathrm{g} / \mathrm{kg}$ & 2.52 & 7.49 & 7.92 & 2.97 & 3.51 \\
\hline Total CO Emissions During Test & & 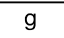 & 439 & 339 & 282 & 326 & 145 \\
\hline$\%$ of Total CO Emissions Occuring During Startup & & $\%$ & $25.2 \%$ & $35.2 \%$ & $14.4 \%$ & $20.6 \%$ & $13.1 \%$ \\
\hline$\%$ of Total CO Emissions Occuring During Refuel & & $\%$ & $10.9 \%$ & $45.6 \%$ & $57.0 \%$ & NA & $44.7 \%$ \\
\hline
\end{tabular}

\section{Discussion}

In each LBNL emissions test, the chimney emission estimates are lower than the exhaust emission estimates. As noted previously, although the chimney method has been the most commonly used measurement technique for evaluating stove emissions, measurement errors associated with this technique may be large. We observed 
several anomalies with the chimney dilution sample line during the testing and the results are reported only for comparison and completeness. Several times we noted a significant drop in the measured concentration in the chimney dilution line. The concentration measured in the chimney dilution line converted to chimney concentration was almost always lower than the value measured with the exhaust dilution tunnel sample line. This occurred even after switching the DustTrak particle sampler used on the two lines. The gas phase measurements from the chimney dilution line did not indicate complete plugging of the line, but particles may have been lost to the walls of the collection cone in the chimney or the sample transfer line from chimney to instrument. In addition to errors caused by deposition of particles in the dilution apparatus, we also reiterate our concern about the practice of sampling aerosol at the base of the chimney before it has had time to fully evolve; chimney PM may be lower than dilution tunnel PM simply because aerosol did not have a chance to nucleate and grow before being "frozen" by the dilution apparatus.

A comparison of minute-by-minute PM estimates indicates the frequency with which the chimney method understated PM emissions compared to the exhaust method in our study (Figure 5). The bold 45-degree line indicates 1:1 data coorespondance where the exhaust measure of PM equals the chimney measure. Points below that line indicate exhaust estimates that exceeded the corresponding chimney estimates; points above the line indicate chimney estimates that exceeded the exhaust estimates. It is immediately apparent that the chimney estimates were lower than exhaust estimates in all but a few test observations. Of 1,886 emission estimates shown in the figure, all but 23 fall below the $1: 1$ line.

This tendency for the chimney method to understate PM emissions appears to be in rough proportion to the emission level. This is suggested by power regression curves relating chimney to exhaust emissions in four test runs (Figure 5). The regression curves slant below and away from the 1:1 line at higher emission levels. The regression coefficients suggest that the chimney method missed about 5\% of the PM emissions in the early and large refuel runs and $17 \%$ of PM emissions in the late refuel run, relative to exhaust method estimates.

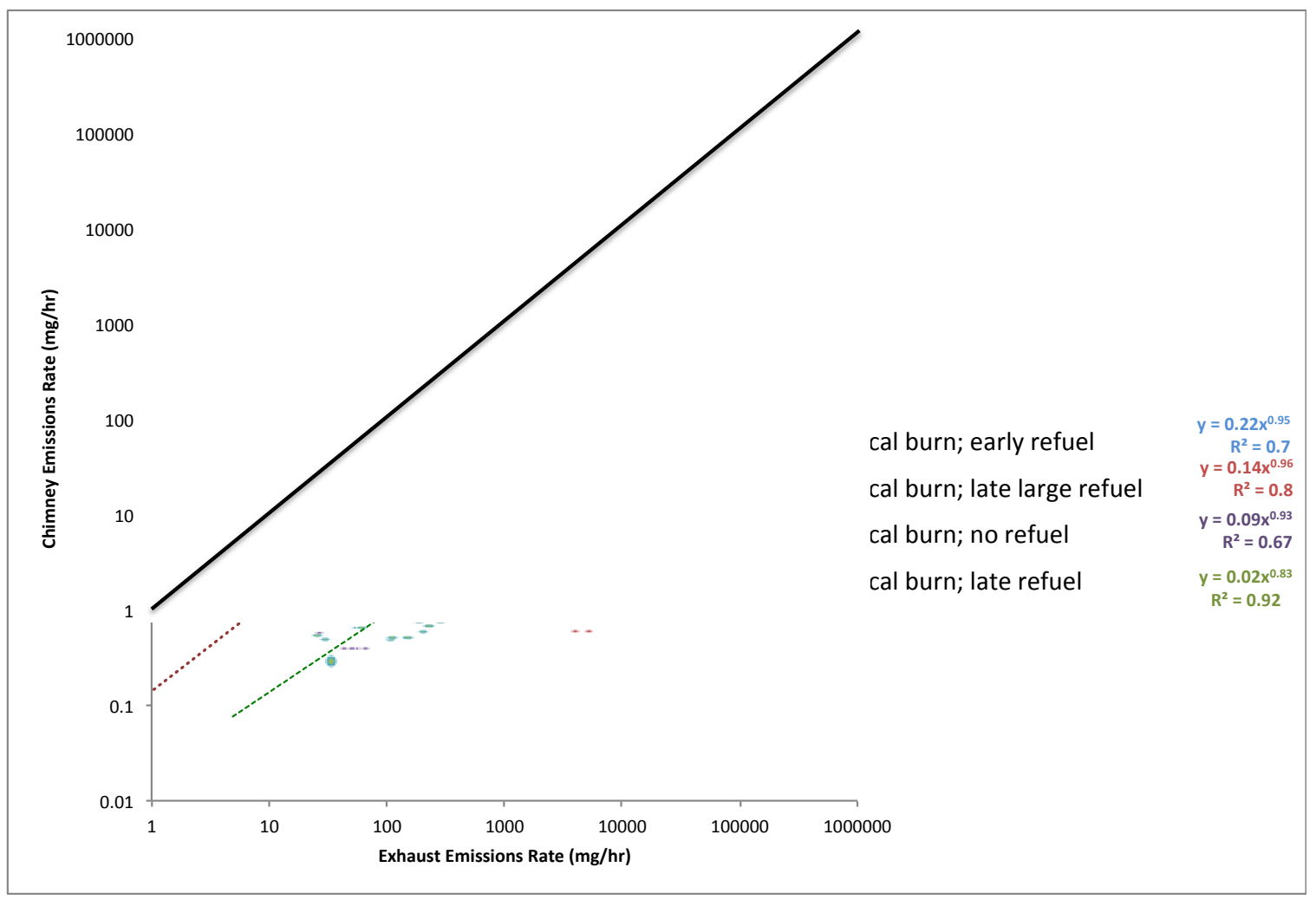

Figure 5. Comparison of exhaust and chimney emission detection

The chimney method emission estimates obtained in this study are consistent with the relatively low estimates reported in other studies using this direct chimney dilution method, including studies by the Building Energy Efficiency Center (BEEC) (Munkhbayar et al. 2011) and the Asian Development Bank (ADB) (ADB/ 
Pemberton-Pigott, 2010). The BEEC study estimated emissions from the Silver mini in different households over several fuel cycles including, presumably, late and early refueling. The ADB study measured Silver mini emissions in a laboratory setting without refueling of any type.

Obviously, emission estimates vary widely across these studies (Table 2). Differences in stove use practices explain much of the observed range. For example, emission estimates applying the chimney method range between $.03(\mathrm{~g} / \mathrm{Kg})$ without refueling and $2.3(\mathrm{~g} / \mathrm{Kg})$ with late refueling. However, differences in measurement technique error may also explain some of the variation as illustrated in Figure 5. For example, emissions estimated using the chimney technique are generally lower, and sometimes much lower, than emissions measured using the exhaust technique.

Table 2. Total PM Emission Factor $(\mathrm{g} / \mathrm{Kg})$--Selected Studies and Measurement Techniques

\begin{tabular}{|c|c|c|c|c|c|c|}
\hline \multirow{2}{*}{ Studies } & \multirow{2}{*}{ Study Type } & \multirow{2}{*}{ Test Type } & \multirow{2}{*}{ Unit } & \multicolumn{3}{|c|}{$\begin{array}{c}\text { Emission Factor Estimates Small-Turkish } \\
\text { Stoves }\end{array}$} \\
\hline & & & & No Refuel & Early Refuel & Late Refuel \\
\hline LBNL & Lab & Exhaust & $\mathrm{g} / \mathrm{kg}$ & 2.97 & 2.52 & 7.49 \\
\hline LBNL & Lab & Chimney & $\mathrm{g} / \mathrm{kg}$ & 0.33 & 1.45 & 2.30 \\
\hline BEEC & Lab & Chimney & $\mathrm{g} / \mathrm{kg}$ & & \multirow{2}{*}{\multicolumn{2}{|c|}{1.70}} \\
\hline ADB & Lab & Chimney & $\mathrm{g} / \mathrm{kg}$ & 0.03 & & \\
\hline \multicolumn{7}{|l|}{ Source } \\
\hline LBNL & \multicolumn{6}{|l|}{ This study. } \\
\hline BEEC & \multirow{2}{*}{\multicolumn{6}{|c|}{$\begin{array}{l}\text { Munkhbayar et. al. March 2011. "Results of Field Testing for Stoves, Gas and Electric Heater". } \\
\text { Building Energy Efficiency Center." MCA Mongolia. Tbl } 12 . \\
\text { ADB/Crispin Pemberton-Pigott. "Test 115." Stove Emissions and Efficiency Testing Laboratory. } \\
\text { December 2010. Section 6.5. Pg 8. }\end{array}$}} \\
\hline$A D B$ & & & & & & \\
\hline
\end{tabular}

The finding that much of the observed range of emission estimates may be due to measurement error and bias suggests, as a policy measure, that priority should be given to increasing the accuracy and relevance of the techniques used to measure emissions - either through improved calibration of existing measurement techniques or through development of new techniques.

Based on this evaluation of uncertainty and variability, we recommend additional laboratory study of the emissions from the Turkish mini and other approved stoves to confirm the accuracy of the exhaust technique in the lab and improve the accuracy of the chimney technique in the field.

\section{Acknowledgments}

The authors are extremely grateful to Crispin Pemberton-Pigott (New Dawn Engineering, Swaziland, Southern Africa), who generously shared from his experience testing and improving space heating stoves and details about the design of his direct chimney dilution apparatus. We thank the Gadgil Lab's Cookstove Research Facility (University of California, Berkeley (UCB) and LBNL) for sharing instrumentation and the capable team of students. We thank Iain Walker (LBNL) for calculations of the standard chimney draft used in this project and are grateful to Henrik Wallman (UCB and LBNL) for stimulating conversations, interesting anecdotes, and challenging questions.

This report was prepared as a result of work sponsored by the Millennium Challenge Corporation, U.S. under Federal Interagency Agreement MCC-10-0064-IAA-80, the California Energy Commission Public Interest Energy Research Program, Energy-Related Environmental Research Program, award number 500-09-049and by the U.S. Department of Energy under Contract No. DE-AC02-05CH11231.

\section{Disclaimer}

This document was prepared as an account of work sponsored by the United States Government. While this document is believed to contain correct information, neither the United States Government nor any agency thereof, nor The Regents of the University of California, nor any of their employees, makes any warranty, express or implied, or assumes any legal responsibility for the accuracy, completeness, or usefulness of any 
information, apparatus, product, or process disclosed, or represents that its use would not infringe privately owned rights. Reference herein to any specific commercial product, process, or service by its trade name, trademark, manufacturer, or otherwise, does not necessarily constitute or imply its endorsement, recommendation, or favoring by the United States Government or any agency thereof, or The Regents of the University of California. The views and opinions of authors expressed herein do not necessarily state or reflect those of the United States Government or any agency thereof, or The Regents of the University of California.

\section{References}

ADB/ Pemberton-Pigott C. (December 2010). “Test 115.” Stove Emissions and Efficiency Testing Laboratory. Section 6.5, pg. 8.

Allen, R.W., Gombojav, E., Barkhasragchaa, B., Byambaa, T., Lkhasuren, O., Amram, O., Takaro, T. K., \& Janes, C. R. (2013). "An assessment of air pollution and its attributable mortality in Ulaanbaatar, Mongolia" Air Quality. Atmosphere \& Health, 6(1), 137-150. http://dx.doi.org/10.1007/s11869-011-0154-3

Boman, C., Nordin, A., Westerholm, R., \& Pettersson, E. (2005). "Evaluation of a constant volume sampling setup for residential biomass fired appliances - influence of dilution conditions on particulate and PAH emissions". Biomass and Bioenergy, 29, 258-268. http://dx.doi.org/10.1016/j.biombioe.2005.03.003

Boman, C., Pettersson, E., Westerholm, R., Bostrom, D., \& Nordin, A. (2011). "Stove Performance and Emission Characteristics in Residential Wood Log and Pellet Combustion, Part 1: Pellet Stoves". Energy Fuels, 25, 307-314. http://dx.doi.org/10.1021/ef100774x

Davy, P. K., Gunchin, G., Markwitz, A., Trompetter, W. J., Barry, B. J., Shagjjamba, D., \& Lodoysamba, S. (2011). "Air particulate matter pollution in Ulaanbaatar, Mongolia: determination of composition, source contributions and source locations". Atmospheric Pollution Research, 2, 126-137. http://dx.doi.org/10.5094/APR.2011.017

Gullett, B. K., Touati, A., \& Hays, M. D. (2003). "PCDD/F, PCB, HxCBz, PAH, and PM Emission Factors for Fireplace and Woodstove Combustion in the San Francisco Bay Region". ES\&T, 37(9), 1758-1765. http://dx.doi.org/10.1021/es026373c

Iyer, M., Wallman, H., \& Gadgil, A. (Draft October 2010). Strategies for Reducing Particulate Emissions from Space Heating in the Ger District of Ulaanbaatar, Mongolia. Lawrence Berkeley National Laboratory Report Number LBNL-Draft.

Lobscheid, A., Fitts, G., Lodoysamba, S., Maddalena, R., \& Dale, L. (2014). "Pilot Study of Fuel and Stove Use Behavior of Mongolian Ger Households". Lawrence Berkeley National Laboratory Report LBNL-6543E Retrieved from http://escholarship.org/uc/item/9sr4r2mf\#page-1

Lodoyasamba, S., \& Pemberton, P. C. (2011). Mitigation of Ulaanbaatar city's air pollution - from source apportionment to ultra-low emission lignite burning stoves (pp. 27-30). Proceedings of the 19th International Conference Domestic Use of Energy, 12-13 April, Cape Town. ISBN 978-0-9814311-4-7.

Maddalena, R, Lunden, M., Wilson, D., Ceballos, C., Kirchstetter, T., Slack, J., \& Dale, L. (2013). "Quantifying Stove Emissions Related to Different Use Patterns for the Silver-mini (Small Turkish) Space Heating Stove" Lawrence Berkeley National Laboratory. October, 2013, Report LBNL-6319E. Retrieved from $\mathrm{http}: / /$ eetd.lbl.gov/publications/quantifying-stove-emissions-related-t

Munkhbayar et al. (March 2011). "Results of Field Testing for Stoves, Gas and Electric Heater.” Building Energy Efficiency Center. MCA Mongolia. Tbl 11.

Pemberton-Pigott C. (2011). Development of a low smoke Mongolian coal stove using a heterogeneous testing protocol. Proceedings of the 19th International Conference Domestic Use of Energy, 12-13 April, Cape Town. ISBN 978-0-9814311-4-7, pp. 65-70.

Pettersson, E., Boman, C., Westerholm, R., Bostrom, D., \& Nordin, A. (2011). "Stove Performance and Emission Characteristics in Residential Wood Log and Pellet Combustion, Part 2: Wood Stoves". Energy Fuels, 25, 315-323.

Pettersson, E., Lindmark, F., Ohman, M., Nordin, A., Westerholm, R., \& Boman, C. (2010). "Design changes in a fixed-bed pellet combustion device: effects of temperature and residence time on emission performance" Energy Fuels, 24, 1333-1340.

Purvis, C. R., McCrillis, R. C., \& Kariher, P. H. (2000). "Fine Particulate Matter (PM) and Organic Speciation of Fireplace Emissions". ES\&T, 34(9). http://dx.doi.org/10.1021/es981006f 
World Bank. (2011). Main report. Vol. 1 of Air quality analysis of Ulaanbaatar: improving air quality to reduce health impacts. Washington, DC: World Bank. Retrieved from http://documents.worldbank.org/curated/en/2011/12/15633946/air-quality-analysis-ulaanbaatar-improving-a ir-quality-reduce-health-impacts-vol-1-2-main-report

\section{Copyrights}

Copyright for this article is retained by the author(s), with first publication rights granted to the journal.

This is an open-access article distributed under the terms and conditions of the Creative Commons Attribution license (http://creativecommons.org/licenses/by/3.0/). 